\title{
Cognitive Changes after Deep Brain Stimulation in Parkinson's Disease: A Critical Review
}

\author{
Raja Mehanna* \\ University of Texas Health Science Center, Houston, Texas, USA
}

"Corresponding author: Raja Mehanna, Department of neurology, University of Texas Health Science Center at Houston, 6410 Fannin Street, Suite 1010, Houston, Texas 77030, USA, Tel: 8323257080; Fax: 713.512.2239; E-mail: raja.mehanna@uth.tmc.edu

Received date: Feb 4, 2014, Accepted date: Feb 24, 2014, Published date: Mar 10, 2014

Copyright: (C) 2014 Raja Mehanna. This is an open-access article distributed under the terms of the Creative Commons Attribution License, which permits unrestricted use, distribution, and reproduction in any medium, provided the original author and source are credited.

\begin{abstract}
Concern about cognitive worsening, especially after subthalamic nucleus (STN) deep brain stimulation (DBS) has been reported in Parkinson's disease (PD) patients, although it has not been deemed severe enough to discredit DBS as a powerful tool in the armamentarium against PD. We here provide an in-depth and critical review of the current literature on this topic, summarizing the available data on the impact of STN and globus pallidus interna (GPi) DBS on each of the following cognitive domains: language, executive function, attention and concentration, memory, visual function, psychomotor and processing speed, and global cognition; then looking in more details into controlled studies as well as studies directly comparing GPi and STN DBS. We conclude that worsening of one or more cognitive function is rare and subtle after DBS in PD patients, without negative impact on quality of life, and that there is very little data supporting that STN DBS has a worse cognitive outcome than Gpi DBS.
\end{abstract}

Keywords: Deep brain stimulation; Subthalamic nucleus; Globus pallidus interna; Parkinson's disease; Cognitive

\section{Abbreviations:}

DBS: Deep Brain Stimulation; STN: Subthalamic Nucleus; GPi: Globus Pallidus Interna; PD: Parkinson 's disease; LID: Levodopa Induced Dyskinesias; DLPFC: Dorsolateral Prefrontal Cortex

\section{Introduction}

Parkinson's disease (PD) is a neurodegenerative disorder characterized by the clinical tetrad of tremor at rest, rigidity, akinesia (or bradykinesia) and postural instability (TRAP). It has a prevalence of 1 to $2 \%$ above the age of 60 years [1] and typically develops between the ages of 55 and 65 years. Pathologically, PD is classified as a synucleinopathy, associated predominantly with the loss of dopaminergic neurons in the substantia nigra, but other brainstem neurons have been found to degenerate in $\mathrm{PD}$, possibly contributing to not only motor but also non-motor impairment [2]. Indeed, PD is now considered to be a complex syndrome with neurobehavioral, autonomic, dermatological, sensory and special sense disorders [3]. Many studies have also reported cognitive changes, including impairments in language, executive function, vision, memory, and psychomotor speed [4-7].

For the last 50 years, levodopa has been the cornerstone of PD management. However, five years after initiation of therapy, a majority of patients develop medication related motor complications, namely levodopa induced dyskinesias (LID) and motor fluctuations. LID are choreic, stereotypic, and dystonic movements affecting any part of the body [2] and occurring either at peak dose or when the medication is kicking in or wearing off (dyskinesia-improvement-dyskinesia effect). Motor fluctuations occur when the duration of each medication dose is too short and the symptoms of PD recur sooner that initially. Deep brain stimulation (DBS) of the subthalamic nucleus (STN) or the globus pallidus pars interna (GPi) grant to patients with PD improved quality of life and decreased motor complications, and has been approved as such by the Food and Drug Administration in the US in 2002 [8]. However, the cognitive impact of DBS in PD patients is unclear, with various studies producing conflicting results. We here endeavor to review the available literature on this subject.

\section{Methods}

Studies were reviewed if they were published in the English language and met our minimum inclusion criteria: 1) at least five subjects followed for a mean of at least 3 months postoperatively, 2) pre- and post-operative cognitive data using at least one standardized measure.

We will first briefly discuss the possible mechanism of action of DBS, then summarize the available data on the impact of STN and GPi DBS on each of the following cognitive domains: language, executive function, attention and concentration, memory, visual function, psychomotor and processing speed, and global cognition. We will then look in more details into controlled studies as well as studies directly comparing GPi and STN DBS.

\section{Pathophysiology of PD, and Possible Mechanism of Action of DBS}

Different motor and non-motor cortical areas project primarily to the striatum which has two major projections: the direct pathway to the GPi and the indirect projection to the GPi via the globus pallidus pars externa and the STN. The GPi serves as the major output nucleus, which connects back to the cortex via the thalamus. Modulated by the substantia nigra pars compacta, the indirect pathway exerts surround inhibition and thus facilitates an excitatory drive to muscles responsible for a given movement and suppresses unwanted motor activity not relevant to the primary movement. Thus, $\mathrm{PD}$ is thought to result from overactivation of the indirect pathway leading to an 
Citation: Mehanna R (2014) Cognitive Changes after Deep Brain Stimulation in Parkinson's Disease: A Critical Review. Brain Disord Ther 3:

Page 2 of 10

increased output from the GPi and a decrease in spontaneous movement [8]. This model of the basal ganglia and its connections is, of course, an oversimplification of a complex network that, when disrupted, can result in a range of motor abnormalities [9]. For example, a hyperdirect pathway, projecting directly from the cortex to the STN, and from there to the GPi had recently been added to this model [10]. While it is unclear how the loss of dopaminergic neurons leads to the cardinal symptoms of $\mathrm{PD}$, animal research as well as human recording have provided functional and biochemical evidence that bradykinesia in PD results from excessive activity in the STN and the GPi [11-13], while the rest tremor most likely results from dysfunction of both the striato-pallidal-thalamocortical and the cerebello-dentato-thalamocortical circuits [14], with hyperactivity and hypersynchronization between central oscillators [15].

DBS acts through delivering an electrical current in a specific target area of the brain. This current can be modulated through modification of voltage, frequency and duration of each electrical pulse delivered. The delivered energy creates an electrical field of variable size and shape according to the parameters used for stimulation. Although initially believed to stimulate the target, thus the name of the whole process, it seems that DBS actually excites the neuronal fibers but inhibits the neural cells $[16,17]$. Overall, DBS leads to modifications of the firing rate and pattern of neurons [18] in the basal ganglia, as well as local release of neurotransmitters such as glutamate and adenosine [19-21]. In addition, it seems that DBS also increases blood flow and stimulates neurogenesis [22]. However, it is unclear how these changes actually modify the symptoms of Parkinson's disease, and DBS is more of an empirically proven treatment in search of physiological explanation.

\section{Cognitive Changes after DBS}

54 studies totaling 1296 STN DBS patients and 85 GPi DBS patients were reviewed. Among these, only 10 included statistical correction for multiple analyzes [23-32] and 13 had a control arm [23,24,28,33-42].

All these studies were reviewed with post hoc corrections for multiple analyzes when required. Our findings are summarized below (Tables 1 and 2).

Studies assessing cognitive change in PD patients after STN DBS

\begin{tabular}{|c|c|c|c|c|c|c|c|}
\hline Author, year & $\mathbf{N}$ & $\begin{array}{l}\mathrm{F} / \mathrm{u} \\
(\mathrm{mo})\end{array}$ & Controlled & $\begin{array}{l}\text { Status of stimulation/ medication } \\
\text { at cognitive assessment }\end{array}$ & $\begin{array}{l}\text { Cognitive } \\
\text { improvement }\end{array}$ & $\begin{array}{l}\text { Cognitive } \\
\text { decline }\end{array}$ & No change \\
\hline Alberts et al. [25] & 8 & N/A & No & UL, BL, ON and OFF/ON & None & E & None \\
\hline Alegret et al. [62] & 15 & 3 & No & ON/OFF & None & None & $\begin{array}{l}\mathrm{E}, \mathrm{PS}, \mathrm{E}, \mathrm{L}, \mathrm{M} \text {, } \\
\mathrm{V}\end{array}$ \\
\hline Ardouin et al. [32] & 49 & $3-6$ & No & ON/inconstant & E & L & GC, E, PS \\
\hline Castelli et al. [44] & 72 & 15 & No & ON/- & $E$ & L & $\mathrm{E}, \mathrm{L}, \mathrm{M}$ \\
\hline Castelli et al. [78] & 19 & 17 & No & ON/ON & None & L & $\mathrm{E}, \mathrm{V}, \mathrm{M}, \mathrm{L}$ \\
\hline Castelli et al. [36] & 27 & 12 & Yes & ON/ON & None & L & $\mathrm{E}, \mathrm{A} / \mathrm{C}, \mathrm{M}, \mathrm{L}$. \\
\hline Cilia et al. [23] & 20 & 12 & Yes & ON/ON & None & L & GC, L, E, A/C \\
\hline Contarino et al. [79] & 11 & 60 & No & ON/ON & None & None & $L, V, M, E$ \\
\hline Daniele et al. [46] & 20 & 12 & No & ON or OFF/ON & None & L & $\begin{array}{l}\mathrm{GC}, \mathrm{L}, \mathrm{E}, \mathrm{A} / \mathrm{C} \text {, } \\
\mathrm{M}\end{array}$ \\
\hline De Gaspari et al. [28] & 12 & 12 & Yes & ON/ON & None & L & \\
\hline Dujardin et al. [80] & 9 & 3 & No & ON/ON & None & None & GC, E, M, PS, L \\
\hline Erola et al. [81] & 19 & 12 & No & ON/ON & None & L & GC, E, PS \\
\hline Fasano et al. [45] & 16 & 96 & No & ON/ON & None & $\mathrm{E}, \mathrm{L}, \mathrm{M}$ & GC,M, E, L \\
\hline Fraraccio et al. [50] & 15 & 16 & No & ON and OFF/ON & None & $\mathrm{A} / \mathrm{C}$ & $\begin{array}{l}\mathrm{E}, \mathrm{A} / \mathrm{C} \\
\mathrm{M}, \mathrm{L}, \mathrm{V}, \mathrm{CG}\end{array}$ \\
\hline Funkiewiez et al. [82] & 50 & $12 \mathrm{a}$ & No & ON/OFF & None & None & $\mathrm{GC}, \mathrm{E}$ \\
\hline Funkiewiez et al. [29] & 70 & 36 & No & ON/69\%OFF & None & L & GC, E, M, PS \\
\hline Gironell et al. [33] & 8 & 6 & Yes & ON/ON & None & None & $\begin{array}{l}\mathrm{L} E, \mathrm{~A} / \mathrm{C}, \mathrm{M}, \mathrm{V} \text {, } \\
\mathrm{PS}\end{array}$ \\
\hline Halbig et al. [47] & 12 & 16 & No & ON and OFF/ON & None & None & PS M GC, E, L \\
\hline Heo et al., [83] & 46 & 12 & No & ON/ON & None & None & $\mathrm{GC}, \mathrm{A} / \mathrm{C}, \mathrm{M}, \mathrm{L}, \mathrm{E}$ \\
\hline Hershey et al. [56] & 24 & $7 \mathrm{~b}$ & No & ON and OFF/OFF & None & E & None \\
\hline
\end{tabular}


Citation: Mehanna R (2014) Cognitive Changes after Deep Brain Stimulation in Parkinson's Disease: A Critical Review. Brain Disord Ther 3:

Page 3 of 10

\begin{tabular}{|c|c|c|c|c|c|c|c|}
\hline Hilker et al. [34] & 8 & 4 & Yes & ON/- & M & None & $\begin{array}{l}\mathrm{GC}, \mathrm{E}, \mathrm{L}, \mathrm{A} / \mathrm{C}, \\
\mathrm{M}, \mathrm{V}\end{array}$ \\
\hline Jahanshahi et al. [51] & 7 & 12 & No & ON and OFF/OFF & $E, A / C, P S$ & $M$ & None \\
\hline Krack et al. [27] & 42 & 60 & No & ON/ON & None & None & GC, E. \\
\hline Lhommée et al. [84] & 63 & 3 & No & ON/ON & None & L & GC,E. \\
\hline Limousin et al. [59] & 24 & 12 & No & ON/OFF & None & None & $E, L, V, P S$ \\
\hline Moretti et al. [43] & 9 & 12 & Yes & ON/ON & L & L,E & $E, L,, A / C, M, V$ \\
\hline Moro et al., [85] & 7 & 9 & No & ON/ON & None & None & $\mathrm{GC}, \mathrm{E}, \mathrm{L}, \mathrm{M}$ \\
\hline Morrison et al. [35] & 17 & 3 & Yes & ON and OFF/OFF & None & None & $L, A / C, M, E, V$ \\
\hline Page et al. [61] & 12 & N/A & No & ON and OFF/ON & $\mathrm{PS}, \mathrm{A} / \mathrm{C}$ & None & $P S, A / C, E$. \\
\hline Perozzo et al. [58] & 20 & 6 & No & ON/ON and OFF & None & None & $\mathrm{E}, \mathrm{A} / \mathrm{C}, \mathrm{M}, \mathrm{PS}$ \\
\hline Pillon et al., 2000 [6] & 63 & 12 & No & ON and OFF $/ 75 \%$ OFF & None & L & $E, P S ~ L, ~ M$ \\
\hline Rothlind et al.[53] & 15 & 21 & No & ON/ON & None & L & $\mathrm{A} / \mathrm{C}, \mathrm{E}, \mathrm{L}, \mathrm{V}, \mathrm{M}$ \\
\hline Sáez-Zea et al. [41] & 9 & 6 & Yes & ON/ON & None & $\mathrm{L}, \mathrm{A} / \mathrm{C}$ & $A, M, V, E, L$ \\
\hline $\begin{array}{l}\text { Saint-Cyr et al., } 2000 \\
\text { [86] }\end{array}$ & 11 & 12 & No & ON/ON & None & L & $E, L, M, A / C, V$ \\
\hline Saint-Cyr et al. [77] & 99 & 6 & No & ON/ON & QOL & L,E & $\begin{array}{l}\mathrm{E}, \mathrm{L}, \mathrm{A} / \mathrm{C}, \mathrm{M}, \\
\mathrm{PS}\end{array}$ \\
\hline Schüpbach et al. [30] & 37 & 60 & No & ON/ON & None & CG,E & None \\
\hline Smeding et al. [40] & 99 & 6 & Yes & ON/ON & None & $\mathrm{L}, \mathrm{A} / \mathrm{C}$ & $L, M, V S, A / C$ \\
\hline Trepanier et al. [76] & 9 & 6 & No & ON/ON & None & None & $\mathrm{A} / \mathrm{C}, \mathrm{M}, \mathrm{V}, \mathrm{L}, \mathrm{E}$ \\
\hline Whelan et al. [31] & 5 & 3 & No & ON/ON & L & L & None \\
\hline Williams et al. [37] & 19 & 24 & Yes & ON/ON & None & None & $\begin{array}{l}\mathrm{GC}, \quad \mathrm{M}, \mathrm{E}, \quad \mathrm{A} / \\
\mathrm{C}, \mathrm{L}, \mathrm{V}, \mathrm{PS}\end{array}$ \\
\hline Witt et al. [49] & 23 & 12 & No & ON and OFF/ON & None & None & L,E,GC \\
\hline Witt et al. [39] & 60 & 6 & Yes & ON/ON & None & $\mathrm{A} / \mathrm{C}$ & GC, E, L, A/C \\
\hline Witt et al. [38] & 31 & 6 & Yes & ON/ON & None & None & $\mathrm{GC}, \mathrm{A} / \mathrm{C}, \mathrm{L}$ \\
\hline Yágüez et al. [87] & 30 & 9 & No & ON/ON & None & $L, M$ & $\mathrm{GC}, \mathrm{M}, \mathrm{L}, \mathrm{V}, \mathrm{E}$ \\
\hline York et al. [24] & 23 & 6 & Yes & ON/ON & None & M & $\begin{array}{l}\text { GC, E, A/C, M, } \\
\text { L,V, PS. }\end{array}$ \\
\hline Zangaglia et al. [42] & 32 & 96 & Yes & ON/ON & None & L & $\mathrm{GC}, \mathrm{M}, \mathrm{E}, \mathrm{A} / \mathrm{C}$ \\
\hline
\end{tabular}

Table 1: Studies assessing cognitive change in PD patients after STN DBS. PD: Parkinson's disease; STN: subthalamic nucleus; N: number of patients; mo: months; A/C: Attention/Concentration; E: Executive; GC: Global Cognition; L: language; M: Memory; PS: Psychomotor/Processing speed; V: Visual. a: median; b: mean

\section{Studies assessing cognitive change in PD patients after GPi DBS}

\begin{tabular}{|c|c|c|c|c|c|c|c|}
\hline Author, year & N & F/u (mo) & Controlled & $\begin{array}{l}\text { Status of stimulation/ medication } \\
\text { at cognitive assessment }\end{array}$ & Cognitive improvement & $\begin{array}{l}\text { Cognitive } \\
\text { decline }\end{array}$ & No change \\
\hline Ardouin et al. [32] & 13 & $3-6$ & No & ON/inconstant & E & L & GC, E, PS \\
\hline Jahanshahi et al. [51] & 6 & 12 & No & ON and OFF/OFF & None & None & $E, A / C, P S, M$ \\
\hline
\end{tabular}




\begin{tabular}{|l|l|l|l|l|l|l|l|}
\hline Pillon et al. [6] & 13 & 12 & No & ON and OFF/75\%OFF & None & None & E, PS L, M \\
\hline Trepanier et al. [76] & 4 & 6 & No & ON/ON & None & None & A/C,M,V,L,E \\
\hline Rothlind et al. [53] & 14 & 21 & No & ON/ON & None & L & A/C, E, L, V, M \\
\hline Fields et al. [54] & 6 & 5 & No & ON/ON & M & None & GC, E, A/C, V, \\
L, M
\end{tabular}

Table 2: Studies assessing cognitive change in PD patients after GPi DBS.

PD: Parkinson's disease; GPi: globus pallidus interna; N: number of patients; mo: months; A/C: Attention/Concentration; E: Executive; GC: Global Cognition; L: language; M: Memory; PS: Psychomotor/ Processing speed; V: Visual. a: median; b : mean

\section{Language}

\section{Subthalamic nucleus}

Improvement in at least one measure of language was reported by 2 studies $[31,43]$ while 21 reported statistically significant worsening in one or more language function, most often a decrease in fluency; and 30 reported no statistically significant change in at least one assessed measure of language (Table 1). Among these, 16 studies reported no change in any measure of language. It must be noted that the methodology of one of the studies reporting worsening [44] was not available for full review. It is unclear if a Bonferroni correction for multiple analyzes was applied by its authors, and, if not, whether such a correction would change the conclusions. Another study [45] was not corrected for multiple analyzes and no exact $\mathrm{p}$ value was reported. A post hoc correction was not possible either and it is unclear if the reported worsening would have been significant once this correction had been made.

Additionally, 6 Studies compared language $\mathrm{ON}$ and OFF stimulation, in the same patients [35,46-50]. Daniele et al. [46] conducted an uncontrolled trial on 20 patients, with cognitive assessment before bilateral STN DBS implant, then at 3, 6, and 12 months afterwards. Postoperative cognitive assessments were carried out with stimulators turned off at three months, and turned on at six and 12 months. After correcting for multiple analyzes, letter verbal fluency was worse compared to the pre-operative assessment only at 3 months, when the stimulation was OFF, but not at 6 or 12 months, when the stimulation was ON. These results might indicate that a decline in verbal fluency was either attenuated by stimulation and/or more pronounced in the early postoperative stages. However, when corrected for multiple analyzes, Pillon et al. [48], reported worsening of fluency with stimulation ON or OFF at 12 months after implant, but not at 3 months. It must be noted that patients were assessed ON medications in the study of Daniele et al., and OFF medication in the study of Pillon et al., which might suggest a synergistic effect of stimulation and medication on fluency. The 4 other studies could not elicit any statistical difference between ON and OFF stimulation states.

In addition, Funkiewiez et al. [29] reported a series of 70 patients assessed OFF medications before surgery, then OFF medication in
$94 \%$ at 1 year and in $69 \%$ at 3 years. They reported worsening of category fluency and total score of fluency at both post-surgical evaluations compared to baseline, without any further worsening between the two post-surgical evaluations. Age was found to be a predictor of decline in executive functions.

It has been suggested that language worsening in some studies was secondary to the parasagittal trajectory taken for electrode implantation [48,51], since functional activation of the paracingulate and cingulate sulci during word generation was demonstrated on fMRI [52]. On the other hand, decreased fluency was associated with perfusion decrements on single photon emission computed tomography (SPECT) in the left dorsolateral prefrontal cortex, anterior cingulate cortex and ventral caudate nucleus [23], suggesting that STN DBS might impact the cognitive circuit involved in language.

\section{Globus pallidus interna}

Three studies totaling 36 patients showed decline in one or more measure of language, most often fluency, up to 21 months after GPi DBS [53-55]. Tröster et al. [55] reported this deterioration in both ablation and DBS of GPi, supporting a consequence of the procedure itself rather than stimulation. However, this study was not corrected for multiple analyzes and $p$ values were not available for a post hoc correction. It is unclear if such a correction would have modified its conclusion. Additionally, 2 of these studies showed no changes in other measures of language. No change in any measure of language was reported in 2 other studies totaling 17 patients followed up to 12 months (Table 2).

\section{Executive function}

\section{Subthalamic Nucleus}

Three studies reported improvement, and 6 showed worsening in at least one measure of executive function. However, one of these [45] was not corrected for multiple analyzes and no exact $p$ value was reported. A post hoc correction was not possible and it is unclear if the reported worsening would have been significant once this correction had been made. Additionally, 34 studies showed no statistical difference in any assessed measures of executive function (Table 1).

Among the 10 studies comparing executive function $\mathrm{ON}$ and $\mathrm{OFF}$ stimulation [25,35,46-51,56,57], 2 showed worsening of the spatial delayed response under a high but not low memory load condition with stimulation $\mathrm{ON}[25,56]$. Alberts et al. [25] reported a series of 8 
patients with bilateral STN DBS, tested OFF medications and in 3 DBS conditions: OFF bilaterally, ON on the most affected side only, and bilaterally $\mathrm{ON}$. The authors found further worsening in executive functions when multitasking in bilateral compared to unilateral stimulation. On the other hand, Jahanshahi et al. [51] reported improvement of frontal executive functions with stimulation ON while the 7 other studies did not yield any statistically significant change.

In addition, Perozzo et al. [58] reported no change in executive function 6 months after surgery with DBS ON, whether ON or OFF medications.

Jahanshahi et al. [51] suggested that post STN DBS improvement in frontal function, including executive and attention/concentration, might be secondary to a decrease in the excessive inhibitory output from the basal ganglia to the frontal cortex. Limousin et al. [59] additionally reported increased activation of the dorsolateral prefrontal cortex (DLPFC) on PET scan after STN DBS.

\section{Globus pallidus interna}

Ardouin et al. [32] reported improvement of at least one measure of executive function at 6 months while 7 other studies did not report statistically significant change in any measure of executive function up to 21 months after the surgery (Table 2).

\section{Attention and Concentration}

\section{Subthalamic Nucleus}

Jahanshahi et al. [51] reported improvement of all reported measures of attention and concentration (A/C) with stimulation $\mathrm{ON}$ compared to OFF in 7 patients. Page and Jahanshahi [57] partially replicated these results by reporting similar improvement in some, but not all, the reported measures in 12 patients. It must be noted that there was no comparison to the preoperative functioning in these 2 studies. Conversely, Fraraccio et al. [50] reported worsening of at least one measure of A/C 16 months after implant, with no difference between $\mathrm{ON}$ and OFF stimulation. Additionally, 3 studies reported post-operative worsening in at least one measure of A/C, up to 6 months after DBS implant. Finally, 19 other reviewed series, including 2 evaluating patients with stimulators ON and OFF $[35,46]$, reported no statistically significant impact of STN DBS implant and/or stimulation on these cognitive functions. In addition, Perozzo et al. [58] reported no change in attention and concentration 6 months after surgery with DBS ON, whether ON or OFF medications (Table 1).

PET studies have shown that the missing digit task, used by Jahanshahi et al. [51], specifically activates the DLPFC and posterior premotor cortex [60], giving a substratum for the observed improvement since these cortical sites receive input from the STN [61].

\section{Globus Pallidus Interna}

No statistically significant change up to 21 months after GPi DBS implant was reported in 5 studies assessing attention and concentration (Table 2). Among these, Jahanshahi et al. [51] could not detect any changes associated with the stimulation status (ON v/s OFF).

\section{Memory}

\section{Subthalamic Nucleus}

Hilker et al. [34] reported improvement of memory after STN DBS in their series of 8 patients followed for 4 months [34]. The study was not corrected for multiple analyzes and no exact $p$ value was reported. A post hoc correction was not possible and it is unclear if the improvement would have been significant once this correction had been made. On the other hand, 3 studies reported worsening in at least one, but not all, measures of memory, up to 16 months after surgery (Table 1). However, one of these [45] was not corrected for multiple analyzes and no exact $\mathrm{p}$ value was reported. A post hoc correction was not possible and it is unclear if this worsening would have been significant once this correction had been made. In addition, Jahanshahi et al. [51] also reported worsening of memory with stimulation ON compared to OFF. Hälbig et al. [47] reported a series of 12 patients assessed post operatively $\mathrm{ON}$ and OFF stimulation and reported an improvement in non-declarative memory but a worsening in declarative memory with stimulation turned ON. However, when corrected for multiple analyzes these results were not statistically significant.

Finally, 25 other series did not report any statistically significant impact of the surgery and/or stimulation on memory (Table 1). Among these, Perozzo et al. [58] reported no changes 6 months after surgery with DBS ON, whether ON or OFF medications.

\section{Globus pallidus interna}

Fields et al. [54] reported worsening of one, but not all, measures of memory in 6 bilateral GPi DBS patients, followed for 5 months. However, this study was not corrected for multiple analyzes and no exact $\mathrm{p}$ value was reported. A post hoc correction was not possible and it is unclear if this worsening would have been significant once this correction had been made. Conversely, 6 other studies, totaling 66 patients followed for up to 21 months, could not detect a statistically significant change in any measure of memory (Table 2). These included 2 studies comparing OFF and ON stimulation states [48,51].

\section{Visual Function}

\section{Subthalamic Nucleus}

Visual function was not significantly impacted in 17 studies, including 2 assessing patients ON and OFF stimulation [35,50] (Table 1). It has to be noted that Alegret et al. [62] were the first to report a detrimental effects of STN-DBS on visuospatial function. However, this was not statistically significant after correction for multiple analyzes.

\section{Globus pallidus interna}

Tröster et al. [55] reported worsening of one but not all measures of visual function in 9 patients followed for 3 months after bilateral GPi DBS. However, this study was not corrected for multiple analyzes and no exact $\mathrm{p}$ value was reported. A post hoc correction was not possible and it is unclear if this worsening would have been significant once this correction had been made. Conversely, 4 studies totaling 44 patients followed up to 21 months did not detect a statistically significant change in any used measure of visual function (Table 2). 
Visual function is the less frequently investigated cognitive function after DBS. With $U_{C}$ et al. [63] reporting significant deficits on visual attention, visual sensory function, spatial perception, and visuoconstructional abilities in PD patients, visual function might need to be included in future cognitive studies in PD.

\section{Psychomotor and Processing Speed}

\section{Subthalamic Nucleus}

Jahanshahi et al. [51] and Page et al. [57] reported improvement in psychomotor and processing speed with STN stimulation ON compared to OFF. No statistically significant change could be detected in 13 other studies, including in 2 evaluating patients with stimulation $\mathrm{ON}$ and OFF [47,48] and one evaluating patients $\mathrm{ON}$ and OFF medications with stimulation ON [58] (Table 1).

\section{Globus pallidus interna}

No significant change in psychomotor and processing speed from GPi implant with or without stimulation could be detected in 4 studies totaling 52 patients $[32,48,51,64]$ (Table 2 ).

\section{Global Cognition}

\section{Subthalamic Nucleus}

Global cognition was showed to significantly worsen 5 years after surgery in one series of 37 patients evaluated ON stimulation and ON medications [30]. However, this study had no control arm, and the reported worsening might be secondary to the natural evolution of PD [65]. Furthermore, these results could not be replicated in 21 other studies that showed no significant change up to 5 years after surgery, including 6 controlled studies comparing STN DBS patients to nonsurgically treated PD patients $[23,24,37-39,42]$ (Table 1). Aybek et al. [26] calculated the incidence of dementia 3 years after bilateral STN DBS in 50 PD patients, and found it to be $89 / 1000$, comparable to the reported incidence in medically managed PD (42.6 to 112 of 1,000 per year) [66].

\section{Globus pallidus interna}

No statistically significant change in global cognition up to 6 months after surgery could be detected in 3 studies [32,54,55] (Table 2).

\section{Controlled Studies}

Since most of the information available stems from open label uncontrolled series, a major concern is that a detected cognitive worsening might be secondary to the natural history of PD rather than DBS. It is then worthwhile to take a closer look at the few controlled studies available (Table 1).

No difference was detected between DBS and non DBS PD patients in 5 controlled studies. Gironell et al [33] reported 8 PD patients who underwent bilateral STN DBS and compared their evolution 6 months after surgery to 8 age and stage-matched PD patients who refused surgery. Evaluations were done ON medication and ON stimulation, and reported worse semantic verbal fluency in the DBS group. However, when corrected for multiple analyzes, this difference was not statistically significant. In addition, no difference was found in the other cognitive tasks assessed. A year later, Morrison et al. [35] compared 17 PD patients who underwent bilateral STN DBS with 11 non surgically treated PD patients. There was no statistically significant difference at 3 months between the 2 groups. In addition, within the DBS group, there was no difference with stimulation $\mathrm{ON}$ or $\mathrm{OFF}$ at 3 months, or between the stimulation $\mathrm{ON}$ at 3 months and the pre-operative assessment. York et al. [24] compared 23 STN DBS patients to 27 medically managed PD patients and reported worse verbal memory in the DBS group at 6 months. Visual memory, all measures of fluency and other cognitive measures were nonstatistically different between the groups. However, in a follow up to this study, Williams et al. [37] reported on 19 STN patients and 18 medically optimized PD patients 2 years after surgery. While the authors concluded on worsening of some measures of memory, processing and fluency, this was not significant after correction for multiple analyzes. More recently, Sáez-Zea et al. [41] compared the cognitive outcome of 9 bilateral STN DBS patients with 12 nonsurgical PD patients 6 months after surgery. While 4 measures of language and attention, out of the 18 cognitive measures assessed, worsened during that interval, there was no difference between the 2 groups. In addition, a non-statistically significant trend to worse phonemic verbal fluency was observed in the STN-DBS patients but was significantly correlated with reductions in the L -dopa-equivalent daily dose, suggesting that worse fluency observed after STN DBS might in fact be secondary to decrease in the anti-parkinsonian medication. Most recently, Witt et al. [38] randomized 62 STN DBS candidates equally to DBS or optimal medical treatment and reported worsening of semantic fluency 6 months after surgery, with no significant change in letter fluency compared to the non-surgical group. However, this difference was not statistically significant after correction for multiple analyzes. Similarly, the other cognitive measures did not differ between the 2 groups.

In contrast, 6 controlled studies suggested worsening of some cognitive measures after DBS, sometimes mitigated by improvement of others. Moretti et al. [43] reported 9 patients with bilateral STN DBS and compared their evolution 12 months after surgery to 9 nonsurgically treated PD patients. Assessments were done ON stimulation and ON medications, and reported worsening of some executive function as well as semantic and syllabic fluency, but with an increase in control of linguistic production. The other cognitive measures assessed were not different between the 2 groups. Zangaglia et al. [42] reported worsening of verbal fluency in the STN DBS group $(n=32)$ compared to the medically optimized patient group $(n=33) 3$ years after surgery. Other cognitive measures were stable over that period of time and did not differ between the 2 groups. Witt et al [39] compared 60 bilateral STN treated PD patients with 63 STN eligible PD patients who declined surgery ON medications and stimulation 6 months after implant. While this study did not compare cognitive functions to the preoperative baseline, it did nevertheless report statistically worse attention on 2 measures in the STN group, but no difference in the other cognitive measures assessed. Smeding et al. [40] compared 99 STN DBS patients to 39 non DBS patients 6 months after implant in the $\mathrm{ON}$ stimulation/ON medication state. They reported a significantly worse decline in fluency and attention/concentration in the STN group. Other cognitive measures were stable over that period of time and did not differ between the 2 groups. Cilia et al. [23] reported statistically significant worsening of category fluency in a group of $20 \mathrm{DBS}$ patients compared to 12 non-surgically treated PD patients 12 months after surgery. Phonemic fluency and other cognitive measures did not differ between the 2 groups. Last, Castelli 
et al. [36] compared the change in score between pre-operative baseline and 1 year follow up for each assessed cognitive measure, between 27 STN DBS patients and 31 matched non DBS PD patients. Phonemic fluency was worse in the STN group, while semantic fluency and other cognitive measures were not statistically different between the 2 groups.

Hilker et al. [34], however, compared 8 PD patients ON stimulation 4 months after bilateral STN DBS with 10 healthy matched controls and reported significant improvement in verbal and nonverbal longterm memory, suggesting STN DBS might in fact improve memory circuits compared to non-surgically treated PD patients. The study was not corrected for multiple analyzes and no exact $\mathrm{p}$ value was reported. A post hoc correction was not possible and it is unclear if the improvement would have been significant once this correction had been made.

Finally, Whelan et al. [31] compared language between 5 PD patients 3 months after bilateral STN DBS and 16 non surgically treated PD patients. Each of these groups was then compared to another group of 16 healthy aged matched and that difference was again compared between these 2 groups. PD patients were all $\mathrm{ON}$ medications and DBS patients had their stimulators ON. When compared to the non-surgically treated PD patients, post DBS patients had improvement on the word test-revised but decline in the accuracy of lexical decisions about words with many meanings and a high degree of relatedness between meanings. It is unclear however, how much these detailed differential results would impact the patients' daily life.

In summary, only half the available controlled studies reported statistically significant worsening on some cognitive measures after bilateral STN DBS. Different subtypes of fluency (semantic, phonemic, category) worsened in some studies but not others. Worsening of attention was also reported in more than one controlled study. On the other hand, 2 controlled studies reported improvement in some cognitive measure after STN DBS. It thus seems that cognitive worsening after STN DBS should not be taken for granted.

\section{Target Selection}

A current tendency is to prefer GPi DBS for patients with mild cognitive impairment for fear that STN DBS is associated with more cognitive side effects. While there is more data reporting cognitive worsening after STN DBS, this data is markedly imbalanced as the studies detailed above have evaluated 1296 STN DBS patients but only $85 \mathrm{GPi}$ patients. Therefore, we took a closer and more critical look at head to head comparison between the 2 targets.

To our knowledge, 5 studies have compared head to head the cognitive impact of STN and GPi DBS [53,67-70] (Table 3). Only one [67] reported correction for multiple analyses. After corrections were applied when needed, only Weaver et al. [69] reported worsening on one memory test 3 years after STN DBS compared to GPi DBS, in 159 patients. The other studies, totaling 514 subjects (251 STN and 263 GPi) followed up to 2 years, could not detect any statistically significant difference between the 2 targets. While this discrepancy might be explained by the longer follow up in the study of Weaver et al., it is interesting to note that it did not report any worse decline in language, fluency, attention or executive function in the STN group, as would have been expected form the open labeled and nonsurgical patient matched series.

Studies comparing cognitive outcome between GPi and STN DBS in $\mathrm{PD}$ patients

\begin{tabular}{|l|l|l|l|l|l|l|}
\hline Author, year & $\begin{array}{l}\text { N } \\
\text { STN/GPi }\end{array}$ & Laterality & F/u (mo) & $\begin{array}{l}\text { Status of } \\
\text { stimulation/ } \\
\text { medication } \\
\text { cognitive } \\
\text { assessment }\end{array}$ & $\begin{array}{l}\text { Cognitive } \\
\text { measures } \\
\text { assessed }\end{array}$ & $\begin{array}{l}\text { Differences between GPI and } \\
\text { STN }\end{array}$ \\
\hline Rothlind et al. [53] & $19 / 23$ & UL & 6 & ON/ON & A/C,E,L,V,M & None \\
\hline Rothlind et al. [53] & $14 / 15$ & BL & 21 & ON/ON & A/C,E,L,V,M & None \\
\hline Okun et al. [67] & $22 / 23$ & UL & 7 & ON/OFF & L & None \\
\hline Follett et al., 2010 [68] & $147 / 152$ & BL & 24 & ON/OFF & GC, L, V, E, M & None \\
\hline Weaver et al. [69] & $70 / 89$ & BL & 36 & ON/OFF & GC, L, V, E,M & M worse with STN \\
\hline Odekerken et al. [70] & $63 / 65$ & BL & 12 & ON/Integrated ON and & Composite test & None \\
\hline
\end{tabular}

Table 3: Studies comparing cognitive outcome between GPi and STN DBS in PD patients. PD: Parkinson's disease; GPi: globus pallidus interna; STN: subthalamic nucleus; N: number of patients; mo: months; UL: unilateral; BL: bilateral; A/C: Attention/Concentration; E: Executive; GC: Global Cognition; L: language; M: Memory; V: Visual.

\section{Discussion}

As seen above, available studies on the cognitive impact of DBS on PD patients yielded different and sometimes opposite results. However, when cognitive worsening was detected, it was usually not reported by patients, caregiver or health care providers, suggesting that any change revealed by cognitive tests is subtle [32]. In addition, quality of life was improved after DBS, even when cognitive worsening was detected [46].

Kumar et al. [71] suggested that this could reflect some variability in lead placement inside the target. Comparing postoperative magnetic resonance imaging scans in 8 patients who developed neuropsychological side effects to 30 who did not, Tsai et al. [72] suggested that the neuropsychological effects of chronic STN-DBS were related to an anteriorly located active contact within the ventral 
STN. York et al. [73] reported that the surgical trajectory through the frontal lobe, in addition to the precise location of the active electrode inside the STN, might also influence the cognitive outcome. Indeed, Witt et al. [38] reported that a trajectory intersecting the caudate nucleus was associated with a higher risk of decline in global cognition and working memory performance. These results have yet to be duplicated in larger series.

In addition, the stimulation parameters might also influence the outcome. Wojtecki et al. [74] reported improvement of verbal fluency in $12 \mathrm{PD}$ patients with low frequency $(10 \mathrm{~Hz})$ STN DBS compared to no stimulation. Stimulation at $130 \mathrm{~Hz}$ had a non-significant trend towards worsening of fluency compared to no stimulation, suggesting a frequency-dependent modulation of cognitive circuits involving the STN. In another study on 20 PD patients treated with bilateral STN DBS, Schoenberg et al., [75] reported that increased amplitude and pulse width of the stimulation were associated with improved cognitive test scores.

Trepanier et al. [76] also suspected variations in the characteristics of the patients selected for surgery between different centers (age, preoperative cognitive status, comorbidity with other conditions such as psychiatric disorders). While advanced age might be considered a risk factor for cognitive worsening, studies showing executive worsening [25,30,43,45,56,77-80] did not have an older population than studies reporting improvement $[32,44,51]$ (mean age of 56.8 vs. 58 years).

Several methodological issues can be raised when reviewing studies assessing neuropsychological outcome after DBS for PD. First and foremost, observed cognitive decline might be secondary to the natural evolution of the disease. Indeed most the available studies lack a control arm of non-surgically treated PD patients. Second, observed cognitive improvement can result from practice effect in the case of serial neuropsychological assessment [46]. The use of parallel forms of cognitive tasks or the comparison of results with a non-surgically treated group of patients might mitigate this practice effect, although this could be logistically difficult. An alternative would be to use relatively long intervals between cognitive assessments [46]. Third, the pharmacological condition of the patients at the time of neuropsychological test is not uniform across all studies. Patients were assessed $\mathrm{ON}$ anti-parkinsonian drug treatment in most studies, but OFF anti-parkinsonian drug treatment in others $[35,51,56,62,67-69,80-87]$, or even in a non-homogenous way in some [32]. Finally, it is possible that a postoperative reduction in antiparkinsonian drugs, seen more after STN DBS than in GPi DBS [8] could to some extent negatively influence performance on cognitive tasks. This could be minimized by a uniform assessment of all patients ON stimulation and OFF medication. However, this could render preoperative assessment impossible in some patients, because of the severity of their motor symptoms when OFF medications

\section{Conclusion}

We reviewed the available literature on cognitive changes after STN and GPi DBS in PD patients and arrive at the following suggestions. (1) Worsening of one or more cognitive function is rare after DBS in PD patients. Available literature is conflicting, with controlled studies reporting opposite results. (2) When cognitive worsening is detected; it is usually not reported by patients, caregiver or health care providers, suggesting that any change revealed by cognitive tests is subtle. In addition, quality of life is improved after DBS, even when cognitive worsening is detected. (3) Only one in 5 randomized trial comparing cognitive outcome in and STN and GPi DBS reported worse cognitive outcome in the STN group, namely on one measure of memory. While the choice of the target should be individualized and adapted to the patient's situation, fear of cognitive worsening after STN might not have to weight a lot on this decision. (4) Future studies addressing this topic should ideally have a control arm of nonsurgically treated PD patients matched for all clinical and demographic variables to control for the natural evolution of the disease. In addition, assessing the DBS group ON and OFF stimulation would provide direct comparisons of the stimulatory effects while controlling for surgical effects, and yield greater power since patients serve as their own controls. (5) More reports on anatomo-clinical correlation of cognitive worsening after DBS would help improve surgical planning to avoid sensitive structures.

\section{References}

1. Tanner CM, Aston DA (2000) Epidemiology of Parkinson's disease and akinetic syndromes. Curr Opin Neurol 13: 427-430.

2. Mehanna R, Jankovic J (2010) Respiratory problems in neurologic movement disorders. Parkinsonism Relat Disord 16: 628-638.

3. Mehanna R, Jankovic J (2013) Movement disorders in cerebrovascular disease. Lancet Neurol 12: 597-608.

4. Grossman M, Lee C, Morris J, Stern MB, Hurtig HI (2002) Assessing resource demands during sentence processing in Parkinson's disease. Brain Lang 80: 603-616.

5. Lee C, Grossman M, Morris J, Stern MB, Hurtig HI (2003) Attentional resource and processing speed limitations during sentence processing in Parkinson's disease. Brain Lang 85: 347-356.

6. Pillon B, Czernecki V, Dubois B (2003) Dopamine and cognitive function. Curr Opin Neurol 16(Suppl 2): S17-S22.

7. Muslimovic D, Post B, Speelman JD, Schmand B (2005) Cognitive profile of patients with newly diagnosed Parkinson disease. Neurology 65: 1239-1245.

8. Mehanna R, Lai E (2013) Deep Brain Stimulation in Parkinson's Disease. Transl Neurodegener 2: 22.

9. Diederich NJ, Parent A (2012) Parkinson's disease: acquired frailty of archaic neural networks? J Neurol Sci 314: 143-151.

10. Brunenberg EJ, Moeskops P, Backes WH, Pollo C, Cammoun L, et al. (2012) Structural and resting state functional connectivity of the subthalamic nucleus: identification of motor STN parts and the hyperdirect pathway. PLoS One 7:e39061.

11. Jankovic J, Mehanna R (2013) Pathophysiology and clinical assessment. in Handbook of Parkinson's Disease. Rajesh Pahwa , Kelly E Lyons, (5th edn): 61-91.

12. Lintas A, Silkis IG, Albéri L, Villa AE (2012) Dopamine deficiency increases synchronized activity in the rat subthalamic nucleus. Brain Res 1434: 142-151.

13. Dostrovsky JO, Hutchinson WD, Lozano AM (2002) The globus pallidus, deep brain stimulation and Parkinson's disease. Neuroscientist 8: 284-290.

14. Boecker H, Brooks DJ (2011) Resting tremor in Parkinson disease: is the pallidum to blame? Ann Neurol 69: 229-231.

15. Bartolic A, Pirtosek Z, Rozman J, Ribaric S (2010) Tremor amplitude and tremor frequency variability in Parkinson's disease is dependent on activity and synchronisation of central oscillators in basal ganglia. Med Hypotheses 74: 362-365.

16. McIntyre CC, Hahn PJ (2010) Network perspectives on the mechanisms of deep brain stimulation. Neurobiol Dis 38: 329-337.

17. Vitek JL (2002) Mechanisms of deep brain stimulation: excitation or inhibition. Mov Disord 17: S69-S72. 
18. Wichmann T, DeLong MR, Guridi J, Obeso JA (2011) Milestones in research on the pathophysiology of Parkinson's disease. Mov Disord 26: 1032-1041.

19. Tawfik VL, Chang SY, Hitti FL, Roberts DW, Leiter JC, et al. (2010) Deep brain stimulation results in local glutamate and adenosine release: investigation into the role of astrocytes. Neurosurgery 67: 367-375.

20. Lee KH, Chang SY, Roberts DW, Kim U (2004) Neurotransmitter release from high-frequency stimulation of the subthalamic nucleus. J Neurosurg 101: 511-517.

21. Lee KH, Hitti FL, Chang SY, Lee DC, Roberts DW, et al. (2011) High frequency stimulation abolishes thalamic network oscillations: an electrophysiological and computational analysis. J Neural Eng 8: 046001.

22. Vedam-Mai V, van Battum EY, Kamphuis W, Feenstra MG, Denys D, et al. (2012) Deep brain stimulation and the role of astrocytes. Mol Psychiatry 17: 124-131.

23. Cilia R, Siri C, Marotta G, De Gaspari D, Landi A, et al. (2007) Brain networks underlining verbal fluency decline during STN-DBS in Parkinson's disease: an ECD-SPECT study. Parkinsonism Relat Disord 13: 290-294.

24. York MK, Dulay M, Macias A, Levin HS, Grossman R, et al. (2008) Cognitive declines following bilateral subthalamic nucleus deep brain stimulation for the treatment of Parkinson's disease. J Neurol Neurosurg Psychiatry 79: 789-795.

25. Alberts JL, Voelcker-Rehage C, Hallahan K, Vitek M, Bamzai R, et al. (2008) Bilateral subthalamic stimulation impairs cognitive-motor performance in Parkinson's disease patients. Brain 131: 3348-3360.

26. Aybek S, Gronchi-Perrin A, Berney A, Chiuvé SC, Villemure JG, et al. (2007) Long-term cognitive profile and incidence of dementia after STNDBS in Parkinson's disease. Mov Disord 22: 974-981.

27. Krack P, Batir A, Van Blercom N, Chabardes S, Fraix V, et al. (2003) Five-year follow-up of bilateral stimulation of the subthalamic nucleus in advanced Parkinson's disease. N. Engl J Med 349: 1925-1934.

28. De Gaspari D, Siri C, Landi A, Cilia R, Bonetti A, et al. (2006) Clinical and neuropsychological follow up at 12 months in patients with complicated Parkinson's disease treated with subcutaneous apomorphine infusion or deep brain stimulation of the subthalamic nucleus. J Neurol Neurosurg Psychiatry 77: 450-453.

29. Funkiewiez A, Ardouin C, Caputo E, Krack P, Fraix V, et al. (2004) Long term effects of bilateral subthalamic nucleus stimulation on cognitive function, mood, and behaviour in Parkinson's disease. J Neurol Neurosurg Psychiatry 75: 834-839.

30. Schüpbach WM, Chastan N, Welter ML, Houeto JL, Mesnage V, et al. (2005) Stimulation of the subthalamic nucleus in Parkinson's disease: a 5 year follow up. J Neurol Neurosurg Psychiatry 76: 1640-1644.

31. Whelan BM, Murdoch BE, Theodoros DG, Hall B, Silburn P (2003) Defining a role for the subthalamic nucleus within operative theoretical models of subcortical participation in language. J Neurol Neurosurg Psychiatry 74: 1543-1550.

32. Ardouin C, Pillon B, Peiffer E, Bejjani P, Limousin P, et al. (1999) Bilateral subthalamic or pallidal stimulation for Parkinson's disease affects neither memory nor executive functions: a consecutive series of 62 patients. Ann Neurol 46: 217-223.

33. Gironell A, Kulisevsky J, Rami L, Fortuny N, García-Sánchez C, et al. (2003) Effects of pallidotomy and bilateral subthalamic stimulation on cognitive function in Parkinson disease. A controlled comparative study. J Neurol 250: 917-923.

34. Hilker R, Voges J, Weisenbach S, Kalbe E, Burghaus L, et al. (2004) Subthalamic nucleus stimulation restores glucose metabolism in associative and limbic cortices and in cerebellum: evidence from a FDGPET study in advanced Parkinson's disease. J Cereb Blood Flow Metab 24: 7-16.

35. Morrison CE, Borod JC, Perrine K, Beric A, Brin MF, et al. (2004) Neuropsychological functioning following bilateral subthalamic nucleus stimulation in Parkinson's disease. Arch Clin Neuropsychol 19: 165-181.

36. Castelli L, Rizzi L, Zibetti M, Angrisano S, Lanotte M, et al. (2010) Neuropsychological changes 1-year after subthalamic DBS in PD patients: A prospective controlled study. Parkinsonism Relat Disord 16: 115-118.

37. Williams AE, Arzola GM, Strutt AM, Simpson R, Jankovic J, et al. (2011) Cognitive outcome and reliable change indices two years following bilateral subthalamic nucleus deep brain stimulation. Parkinsonism Relat Disord 17: 321-327.

38. Witt K, Granert O, Daniels C, Volkmann J, Falk D, et al. (2013) Relation of lead trajectory and electrode position to neuropsychological outcomes of subthalamic neurostimulation in Parkinson's disease: results from a randomized trial. Brain 136: 2109-2119.

39. Witt K, Daniels C, Reiff J, Krack P, Volkmann J, et al. (2008) Neuropsychological and psychiatric changes after deep brain stimulation for Parkinson's disease: a randomised, multicentre study. Lancet Neurol 7: 605-614.

40. Smeding HM, Speelman JD, Koning-Haanstra M, Schuurman PR, Nijssen P, et al. (2006) Neuropsychological effects of bilateral STN stimulation in Parkinson disease: a controlled study. Neurology 66: 1830-1836.

41. Sáez-Zea C, Escamilla-Sevilla F, Katati MJ, Mínguez-Castellanos A (2012) Cognitive Effects of Subthalamic Nucleus Stimulation in Parkinson's Disease: A Controlled Study Eur Neurol 68: 361-366.

42. Zangaglia R, Pacchetti C, Pasotti C, Mancini F, Servello D, et al. (2009) Deep brain stimulation and cognitive functions in Parkinson's disease: A three-year controlled study. Mov Disord 24: 1621-1628.

43. Moretti R, Torre P, Antonello RM, Capus L, Marsala SZ, et al. (2003) Neuropsychological changes after subthalamic nucleus stimulation: a 12 month follow- up in nine patients with Parkinson's disease. Parkinsonism Relat Disord 10: 73-79.

44. Castelli L, Perozzo P, Zibetti M, Crivelli B, Morabito U, et al. (2006) Chronic deep brain stimulation of the subthalamic nucleus for Parkinson's disease: effects on cognition, mood, anxiety and personality traits. Eur Neurol 55: 136-144.

45. Fasano A, Romito LM, Daniele A, Piano C, Zinno M, et al. (2010) Motor and cognitive outcome in patients with Parkinson's disease 8 years after subthalamic implants. Brain 133: 2664-2676.

46. Daniele A, Albanese A, Contarino MF, Zinzi P, Barbier A, et al. (2003) Cognitive and behavioural effects of chronic stimulation of the subthalamic nucleus in patients with Parkinson's disease. J Neurol Neurosurg, Psychiatry 74: 175-182.

47. Hälbig TD, Gruber D, Kopp UA, Scherer P, Schneider GH, et al. (2004) Subthalamic stimulation differentially modulates declarative and nondeclarative memory. Neuroreport. 15: 539-543.

48. Pillon B, Ardouin C, Damier P, Krack P, Houeto JL, et al. (2000) Neuropsychological changes between "off" and "on" STN or GPi stimulation in Parkinson's disease. Neurology 55: 411-418.

49. Witt K, Pulkowski U, Herzog J, Lorenz D, Hamel W, et al. (2004) Deep brain stimulation of the subthalamic nucleus improves cognitive flexibility but impairs response inhibition in Parkinson disease. Arch Neurol 61: 697-700.

50. Fraraccio M, Ptito A, Sadikot A, Panisset M, Dagher A (2008) Absence of cognitive deficits following deep brain stimulation of the subthalamic nucleus for the treatment of Parkinson's disease. Arch Clin Neuropsychol 23: 399-408.

51. Jahanshahi M, Ardouin CM, Brown RG, Rothwell JC, Obeso J, et al. (2000)The impact of deep brain stimulation on executive function in Parkinson's disease. Brain 123: 1142-1154.

52. Crosson B, Sadek JR, Bobholz JA, Gökçay D, Mohr CM, et al. (1999) Activity in the paracingulate and cingulate sulci during word generation: an fMRI study of functional anatomy. Cereb Cortex 9: 307-316.

53. Rothlind JC, Cockshott RW, Starr PA, Marks WJ Jr (2007) Neuropsychological performance following staged bilateral pallidal or subthalamic nucleus deep brain stimulation for Parkinson's disease. J Int Neuropsychol Soc 13: 68-79.

54. Fields JA, Tröster AI, Wilkinson SB, Pahwa R, Koller WC (1999) Cognitive outcome following staged bilateral pallidal stimulation for the treatment of Parkinson's disease. Clin Neurol Neurosurg 101: 182-188. 
55. Tröster AI, Fields JA, Wilkinson SB, Pahwa R, Miyawaki E, et al. (1997) Unilateral pallidal stimulation for Parkinson's disease: neurobehaviora functioning before and 3 months after electrode implantation. Neurology 49: 1078-1083.

56. Hershey T, Revilla FJ, Wernle A, Gibson PS, Dowling JL, et al. (2004) Stimulation of STN impairs aspects of cognitive control in PD. Neurology 62: 1110-1114.

57. Page D, Jahanshahi M (2007) Deep brain stimulation of the subthalamic nucleus improves set shifting but does not affect dual task performance in Parkinson's disease. IEEE Trans Neural Syst Rehabil Eng 15: 198-206.

58. Perozzo P, Rizzone M, Bergamasco B, Castelli L, Lanotte M, et al. (2001) Deep brain stimulation of the subthalamic nucleus in Parkinson's disease: comparison of pre- and postoperative neuropsychological evaluation. J Neurol Sci 192: 9-15.

59. Limousin P, Krack P, Pollak P, Benazzouz A, Ardouin C, et al. (1998) Electrical stimulation of the subthalamic nucleus in advanced Parkinson's disease. N Engl J Med 339: 1105-1111.

60. Petrides M, Alivisatos B, Meyer E, Evans AC (1993) Functional activation of the human frontal cortex during the performance of verbal working memory tasks. Proc Natl Acad Sci USA 90: 878-882.

61. Halpern CH, Rick JH, Danish SF, Grossman M, Baltuch GH (2009) Cognition following bilateral deep brain stimulation surgery of the subthalamic nucleus for Parkinson's disease. Int J Geriatr Psychiatry 24: 443-451.

62. Alegret M, Junqué C, Valldeoriola F, Vendrell P, Pilleri M, et al. (2001) Effects of bilateral subthalamic stimulation on cognitive function in Parkinson disease. Arch Neurol 58: 1223-1227.

63. Uc EY, Rizzo M, Anderson SW, Sparks J, Rodnitzky RL, et al. (2006) Impaired visual search in drivers with Parkinson's disease. Ann Neurol 60: 407-413

64. Vingerhoets G, van der Linden C, Lannoo E, Vandewalle V, Caemaert J, et al. (1999) Cognitive outcome after unilateral pallidal stimulation in Parkinson's disease. J Neurol Neurosurg Psychiatry 66: 297-304.

65. Hely MA, Reid WG, Adena MA, Halliday GM, Morris JG (2008) The Sydney multicenter study of Parkinson's disease: the inevitability of dementia at 20 years. Mov Disord 23: 837-844

66. Aarsland D, Andersen K, Larsen JP, Lolk A, Nielsen H, et al. (2001) Risk of dementia in Parkinson's disease: a community based, prospective study. Neurology 56: 730-736.

67. Okun MS, Fernandez HH, Wu SS, Kirsch-Darrow L, Bowers D, et al. (2009) Cognition and mood in Parkinson's disease in subthalamic nucleus versus globus pallidus interna deep brain stimulation: the COMPARE trial. Ann Neurol 65: 586-595

68. Follett KA, Weaver FM, Stern M, Hur K, Harris CL, et al. (2010) Pallidal versus subthalamic deep-brain stimulation for Parkinson's disease. N Engl J Med 362: 2077-2091.

69. Weaver FM, Follett KA, Stern M, Luo P, Harris CL, et al. (2012) Randomized trial of deep brain stimulation for Parkinson disease: thirtysix month outcomes. Neurology 79: 55- 65.

70. Odekerken VJ, van Laar T, Staal MJ, Mosch A, Hoffmann CF, et al. (2013) Subthalamic nucleus versus globus pallidus bilateral deep brain stimulation for advanced Parkinson's disease (NSTAPS study): a randomised controlled trial. Lancet Neurol 12: 37-44.

71. Kumar R, Lang AE, Rodriguez-Oroz MC, Lozano AM, Limousin P, et al. (2000) Deep brain stimulation of the globus pallidus pars interna in advanced Parkinson's disease. Neurology 55: S34-S39.
72. Tsai ST, Lin SH, Lin SZ, Chen JY, Lee CW, et al. (2007) Neuropsychological effects after chronic subthalamic stimulation and the topography of the nucleus in Parkinson's disease. Neurosurgery 61: E1024-1029.

73. York MK, Wilde EA, Simpson R, Jankovic J (2009) Relationship between neuropsychological outcome and DBS surgical trajectory and electrode location. J Neurol Sci 287: 159-171.

74. Wojtecki L, Timmermann L, Jörgens S, Südmeyer M, Maarouf M, et al. (2006) Frequency-dependent reciprocal modulation of verbal fluency and motor functions in subthalamic deep brain stimulation. Arch Neurol 63: 1273-1276.

75. Schoenberg MR, Mash KM, Bharucha KJ, Francel PC, Scott JG (2008) Deep brain stimulation parameters associated with neuropsychological changes in subthalamic nucleus stimulation for refractory Parkinson's disease. Stereotact Funct Neurosurg 86: 337-344.

76. Trepanier LL, Kumar R, Lozano AM, Trépanier LL, Kumar R, et al. (2000) Neuropsychological outcome of GPi pallidotomy and GPi or STN deep brain stimulation in Parkinson's disease. Brain Cogn 42: 324-347.

77. Saint-Cyr JA, Albanese A (2006) STN DBS in PD: selection criteria for surgery should include cognitive and psychiatric factors. Neurology 66: 1799-1800.

78. Castelli L, Lanotte M, Zibetti M, Caglio M, Rizzi L, et al. (2007) Apathy and verbal fluency in STN-stimulated PD patients. An observational follow-up study. J Neurol. 254: 1238-1243.

79. Contarino MF, Daniele A, Sibilia AH, Romito LM, Bentivoglio AR, et al. (2007) Cognitive outcome 5 years after bilateral chronic stimulation of subthalamic nucleus in patients with Parkinson's disease. J Neurol Neurosurg Psychiatry 78: 248-252.

80. Dujardin K, Defebvre L, Krystkowiak P, Blond S, Destée A (2001) Influence of chronic bilateral stimulation of the subthalamic nucleus on cognitive function in Parkinson's disease. J Neurol 248: 603-611.

81. Erola T, Heikkinen ER, Haapaniemi T, Tuominen J, Juolasmaa A, et al. (2006) Efficacy of bilateral subthalamic nucleus (STN) stimulation in Parkinson's disease. Acta Neurochir (Wien) 148: 389-394.

82. Funkiewiez A, Ardouin C, Krack P, Fraix V, Van Blercom N, et al. (2003) Acute psychotropic effects of bilateral subthalamic nucleus stimulation and levodopa in Parkinson's disease. Mov Disord 18: 524-530.

83. Heo JH, Lee KM, Paek SH, Kim MJ, Lee JY, et al. (2008) The effects of bilateral subthalamic nucleus deep brain stimulation (STN DBS) on cognition in Parkinson disease. J Neurol Sci 273: 19-24.

84. Lhommée E, Klinger H, Thobois S, Schmitt E, Ardouin C, et al. (2012) Subthalamic stimulation in Parkinson's disease: restoring the balance of motivated behaviours. Brain 135: 1463-1477.

85. Moro E, Scerrati M, Romito LM, Roselli R, Tonali P, et al. (1999) Chronic subthalamic nucleus stimulation reduces medication requirements in Parkinson's disease. Neurology 53: 85-90.

86. Saint-Cyr JA, Trepanier LL, Kumar R, Lozano AM, Lang AE (2000) Neuropsychological consequences of chronic bilateral stimulation of the subthalamic nucleus in Parkinson's disease. Brain 123: 2091-2108.

87. Yágüez L, Costello A, Moriarty J, Hulse N, Selway R, et al. (2013) Cognitive predictors of cognitive change following bilateral subthalamic nucleus deep brain stimulation in Parkinson's disease. J Clin Neurosci 21: 445-450. 